\title{
Study of the Impact of the University on Sustainability in Far West Texas
}

\section{Mr. Anand Raj, The University of Texas at El Paso}

Anand Raj is a Doctoral student in the Environmental Science and Engineering Program at The University of Texas at El Paso. His doctoral studies focus on sustainability in higher education. His interest lies in the three pillars of sustainability which include social, environmental, and economic aspects. He has a master's degree in business with industry experience. His future plan is to use his business experience to promote sustainability which is important in today's world.

\section{Dr. Peter Golding, University of Texas at El Paso}

Director, Center for Research in Engineering \& Technology Education (CREaTE) and Professor in the Department of Engineering and Leadership at UTEP.

\section{Dr. Diane Elisa Golding, University of Texas at El Paso}

Diane is a passionate educator and proponent for K-12 engineering education and the education of future teachers. She is a professor in the College of Education at the University of Texas at El Paso (UTEP). She earned her undergraduate and graduate degrees from UTEP and holds a doctorate from the Rossier School of Education, University of Southern California.

\section{Dr. Scott A. Starks, University of Texas at El Paso}

Dr. Starks is a Professor of Engineering Leadership at the University of Texas at El Paso. He received the Ph.D. in Electrical Engineering from Rice University in 1978 and is a registered Professional Engineer.

\section{Dr. Luis Rene Contreras Sapien, The University of Texas at El Paso}

Ph.D. in Industrial Engineering with an emphasis in Ergonomics at Kansas State University in May 1995. M.S. in Industrial Engineering with an emphasis in Ergonomics and Statistics at at Kansas State University in 1992. M.S. in Electrical Engineering with an emphasis in Power Systems at The Instituto Tecnológico y de Estudios Superiores de Monterrey in Mexico in 1981. B.S. in Industrial \& Electrical Engineering in 1979 at the Instituto Tecnológico de Chihuahua in México.

Associate Professor since 2006 in Industrial, Manufacturing and Systems Engineering Department at The University of Texas at El Paso (UTEP). Undergraduate Program Director from 2010 to 2019. Interim Chair of the Industrial, Manufacturing and Systems Engineering at UTEP August 2013 - May 2014. Graduate Program Director from 2005 to 2010. Before joining UTEP he served as President, Dean, \& Chair in several Mexican universities. More than 30 years of academic experience in US and Mexico.

Teaching and research interests include Ergonomics, Occupational Safety \& Health, Facilities Planning, and Statistics. Taught different engineering courses at undergraduate and graduate levels in those areas. Published education and research results to refereed journal and conference publications. Senior member of the Institute of Industrial and Systems Engineers. Secured education and research grants from the National Science Foundation, National Institutes of Health, Army Research Labs, Society of Manufacturing Engineering Foundation, and others.

\section{Mrs. Suzan Aranda Luna, University of Texas at El Paso}

Suzan Aranda is a Peruvian student in the Environmental Sciences and Engineering Program at University of Texas at El Paso, who is interestred in Sustainability, Conservation, Environmental Policy and Law, and Engineering Education. 


\section{Study of the Impact of the University on Sustainability in Far West Texas}

Introduction

There was a time in history when economic prosperity was considered the only parameter for societal sustainable growth. As we developed, consumption of resources grew at a rate that increased faster than what nature could replenish. Now, the lack of natural resources has reached an alarming point. The irony is that most resources are controlled by a few people and the major population has less access to it [1]. So, it has become important to change the way sustainable growth is viewed, and, along with economic prosperity, social mobility and environmental protection have also gained importance [2]. This perspective comes with the realization that not only are we as a whole society responsible for sustainability but that higher education institutions play a crucial role in sustainable growth [3] and naturally so because it is in a perfect position to understand and solve local problems. Institutions of higher learning create opportunities for regional economic growth. They provide jobs directly or indirectly to the community.

Additionally, they work to solve environmental issues and social problems unique to their respective regions [3].

This is a descriptive paper that focuses on one higher education institution in far West Texas. For the purpose of this paper, the name of the institution is identified with a pseudonym and will be referred to as the Hilltop University. The paper will review three areas in which Hilltop University has increased the sustainability of the region in terms of social parameters, economic advancement, and environmental conservation. I would like to thank Mr. John Sproul and Ms. Ivette Savina for providing valuable information and data which were collected through personal interviews conducted during the month of November 2019.

\section{Social Upliftment}

Academic Institutions engaged in a collaboration for academic excellence as part of a regional leadership council, work for the social mobility of the population of the region. It started in 1991-92 for the purpose of motivating more students of the region to attain post-secondary education. The council comprised of a variety of cross-sector partners and the present collaboration council has 16 members. Members include the president of the Hilltop University, president of the local community college, superintendents of the three regional independent school districts, and representatives of the business, workforce, and economic development in the region [4]. Membership is intended to cover the spectrum of education for the workforce and economic development. The council's mission is to promote and support innovative education and to provide pathways for students to be able to pursue careers and aspirations. Before the initiation of this collaboration, it was found that the majority of college students in the Hilltop University region did not represent the local population which was predominantly Hispanic. Most of the region's Hispanic students did not continue into post-secondary education once they graduated high school and the council saw the need to create opportunities for the region's most underrepresented students to pursue post-secondary studies. With that goal, collaboration among academic institutions was established [5].

One of the most successful strategies has been the emphasis on developing a college-ready cultural mindset. Through collaboration, opportunities were created by independent school districts and with the educational regional service centers to make it possible for primary and 
secondary education students to see themselves as someone that belongs in college settings. Grassroots efforts, such as campus tours and special activities provided young students opportunities to become familiar with majors and degrees. Visiting students participated in activities to help them learn more about the university and the life of a university student. Thus breaking down barriers, especially for first-generation students, which may never have been on a university campus.

The recruitment process for the Hilltop University and the region's community college, in collaboration with independent school districts, ensure that students receive the support they need in their application process, financial aid process, scholarships, and in all other areas that help them achieve success in college. So far the collaboration among different academic institutions has supported hundreds of thousands of students in the region, helping them think of themselves as college students in the future. This entire process begins early in the student's educational experience when the students are in elementary school and the seed is planted towards developing a goal of achieving a college degree.

The university, along with other regional educational institutions, came forward in support of dual credit education. While in high school, students can take courses that count both towards high school credit and university level credit as well. Dual credit allows the student, now enrolled at the university to graduate earlier as course credits have been achieved sooner. Graduation, in turn, enables the student to be able to join the workforce so that they can be of financial help for their family. Financial hardship is a contributing factor in limiting student enrollment at Hilltop, and the region's education leaders were encouraged to find a solution to mitigate this financial burden. Dual credit accreditation required high school teachers to obtain graduate degrees in their field of instruction. To support this unique strategy of the collaboration for the students, special programs were made available for regional high school teachers to earn their master's degrees in their field to qualify to teach dual credit classes. All the strategies mentioned above have increased student enrollment in post-secondary education and this number has continued to increase (Figure 1).

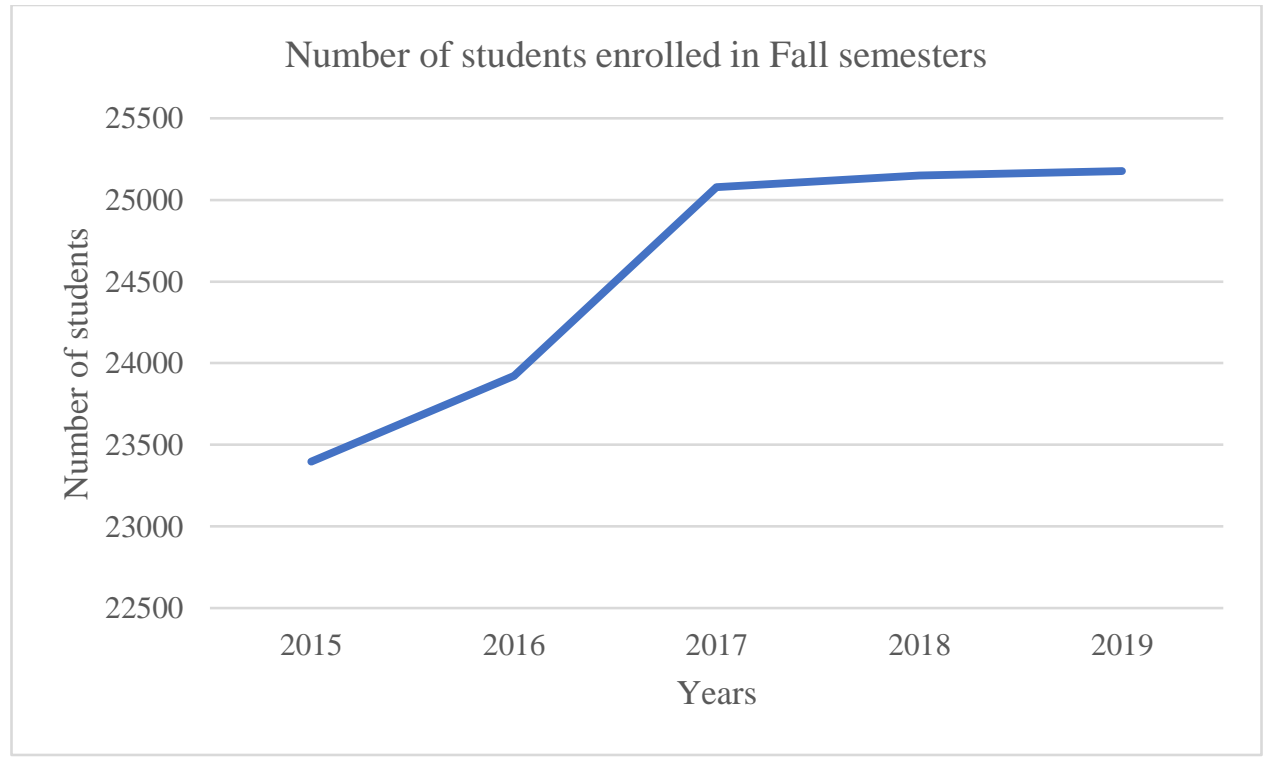

Figure 1: Trend of Increase in enrollment from 2015 - 2019 at Hilltop University [6] 
Hilltop University has built student's social mobility and economic sustainability in the region. Every $\$ 1$ student spend towards their higher education translates to $\$ 3.30$ in return throughout their higher future income. This makes their annual rate of return to be $13.8 \%$ [7]. Obtaining a university-level degree offers opportunities for additional education and financial possibilities, but more importantly, social sustainability is achieved through concepts of hope and aspirations.

\section{Economic Advancement}

Hilltop University is a primary university in the region [4] and it plays an important role and has an influential impact on regional economic development. The most direct economic impact is its operating expenses which include payrolls and benefits, scholarships and fellowships, and research and development. Each parameter can be again bisected into the initial effect and multiplier effect [7]. Local businesses depend on purchases made by the university and business agreements thus indirectly creating many jobs. Additionally, the university is one of the leading employers in the region. According to a report published in 2013, a university such as Hilltop could spend \$200.9 million on payroll and benefits for 3,682 full time and part-time employees and spent another $\$ 234.2$ million on goods and services to carry out its day-to-day operations and research [7]. This initial level of spending creates more spending across other businesses, which is commonly termed as the multiplier effect [8]. Overall, the university contributed $\$ 1.4$ billion towards the economy of the region, which is $5.4 \%$ of the total gross regional product (GRP) of the region [7]. This is equivalent to creating 26,499 jobs [7]. In the same year, the university spent $\$ 167.1$ million on payrolls and benefits to support day to day operations, which added $\$ 294.3$ million to the region's economy creating 4,167 additional jobs [7]. At the same time, $\$ 33.8$ million spent on payroll to support research activities added $\$ 59.3$ million to the region's economy creating 1,147 new jobs [7].

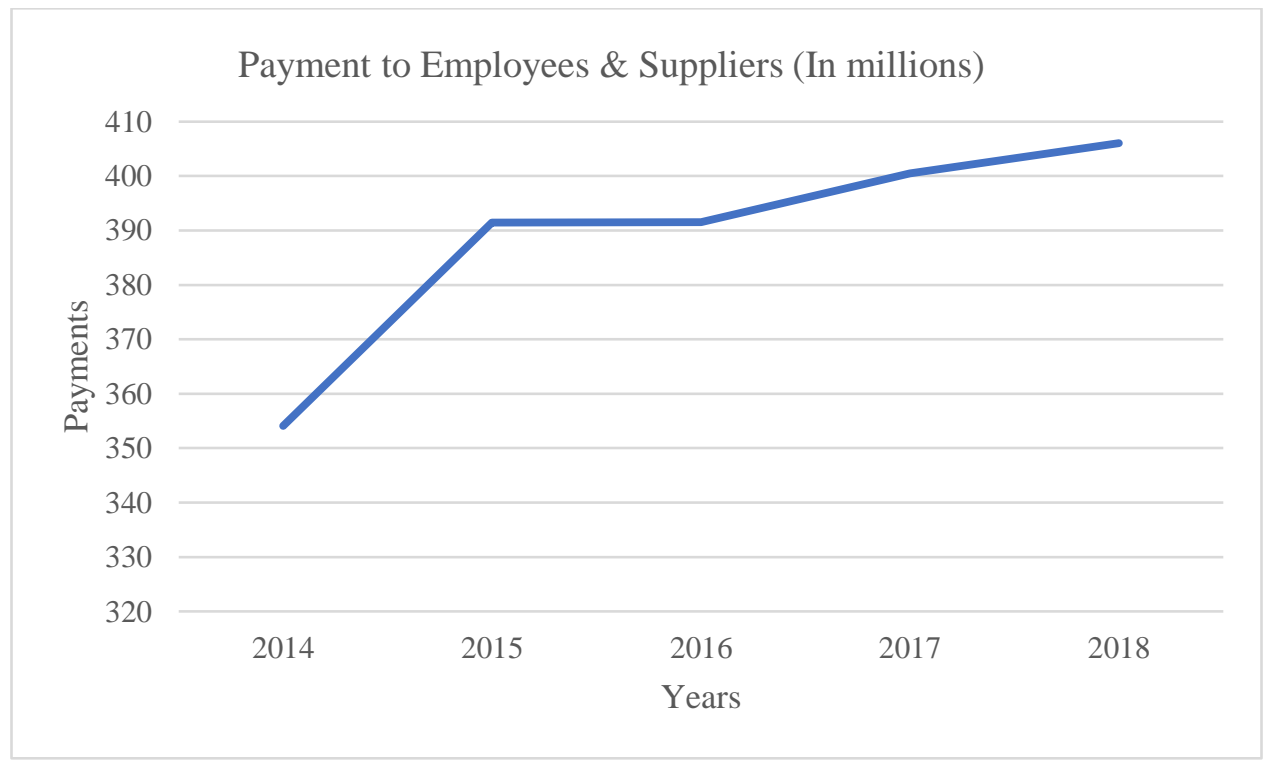

Figure 2a: Expenditure on Payment to Employees \& Suppliers [9] 


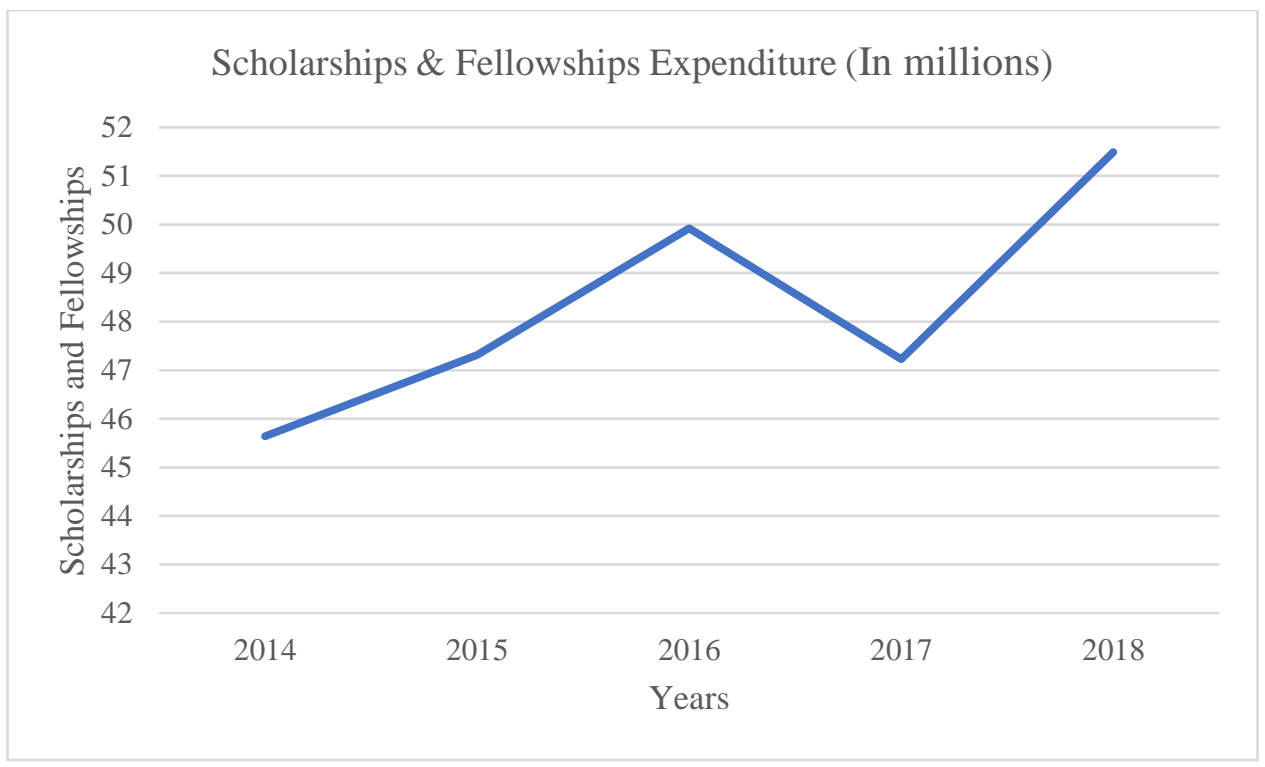

Figure 2b: Expenditure on Scholarships \& Fellowships [9]

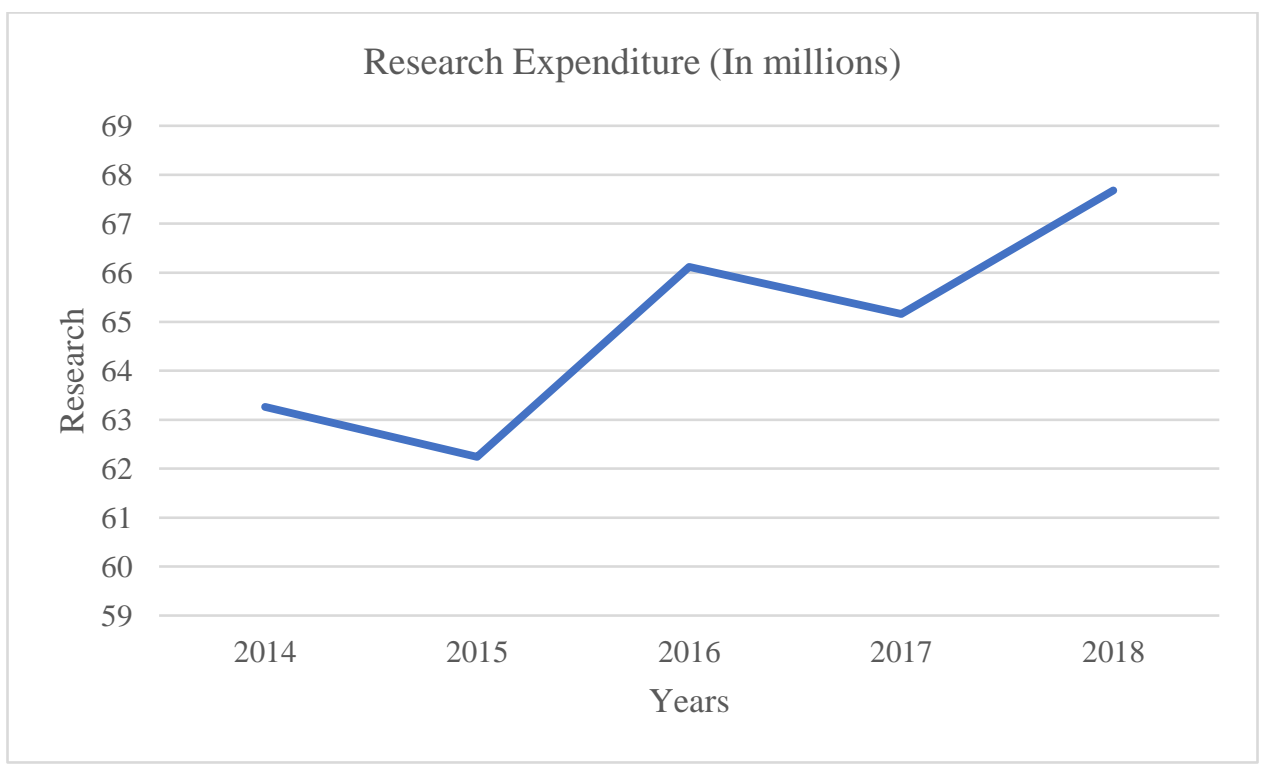

Figure 2c: Expenditure on Research [9]

It is evident (Figure 2a, Figure 2b, Figure 2c) that the economic contributions made by Hilltop University have an upward trend and it can be expected to create more local jobs for the people of this region [8]. An increased level of employment adds to job security and provides a more robust economic foundation. Hilltop University promotes economic sustainability in providing employment opportunities in the university but also in those opportunities which enable graduates to qualify for better-paying jobs. The university values the contribution graduates can make in society and attests to this by hiring some of its own graduates in its mission.

\section{Environmental Conservation}

One of the purest forms of environmental sustainability is exemplified in Hilltop University's role in support of the Wetland Park, the largest park owned by the city. It encompasses 372 acres 
in the area [10], [11]. Initially, in 1973, when the park became a city-owned park, there were some ambitious plans for its development; however, later it was decided to keep it as a natural area with an emphasis on environmental protection [10] and education. This was because the local community wanted restoration of the native ecosystem and some development to make the park more attractive as a site for recreational activity and public visitation but the emphasis was on carrying it forward as a natural area. In 1996, none of the partners of the project came forward to take responsibility for managing the Wetland Park. Finally, Hilltop University was contracted to serve as a manager thereof [10].

Since the region has a dry and semi-arid climate with periods of drought and water scarcity, the biggest challenge the university faced was the water supply. This problem was marginally solved by installing 4 wells in the park [10]. Two of the wells are electric-powered and the other two are solar-powered; however, these only supplied small quantities of water. The largest source of water comes from the region's wastewater treatment plant through a pipeline, which runs from the wastewater treatment plant to Wetland Park. However, water flow to the Wetland Park decreases when water is needed in other parts of the city [10]. Apart from the above two sources of water, irrigation water from the Rio Grande is supplied by an irrigation district [10]. The delivery of water to Wetland Park was made possible after it was classified as an irrigable land. Nonetheless, this source of water depends on the amount of water available for irrigation and it varies throughout the year depending on different factors.

As compared to the past, the increase in water flow from these different water sources has made it possible for vegetation in the Wetland Park to grow and some of the native vegetation has returned: such as cottonwoods and other willows which now flourish in that area. As native vegetation returned, so did natural wildlife. Organisms such as frogs, raccoons, muskrats, turtles, birds came back to this region. Protections were implemented to help the natural vegetation and wildlife continue to grow. The number of bird species increased and, in 1997, there were 107 different bird species out of which 20 species were water birds. In 2019, there were 202 species of birds out of which 78 species were water birds. In spite of the limitations caused by the lack of regular supply of water and worsened by the dry climate, the university has been striving to enable a return of the natural habitat o the region. This is a positive step towards environmental sustainability which also supports research, education, and students from the university and local schools who often visit the area in their academic programs. 
Table 1: Average number of Species from 2007 to 2019

\begin{tabular}{|l|l|}
\hline Year & Average number of species per year \\
\hline 2007 & 31 \\
\hline 2008 & 34 \\
\hline 2009 & 43 \\
\hline 2010 & 37 \\
\hline 2011 & 35 \\
\hline 2012 & 29 \\
\hline 2013 & 30 \\
\hline 2014 & 33 \\
\hline 2015 & 41 \\
\hline 2016 & 43 \\
\hline 2017 & 43 \\
\hline 2018 & 40 \\
\hline 2019 & 36 \\
\hline
\end{tabular}

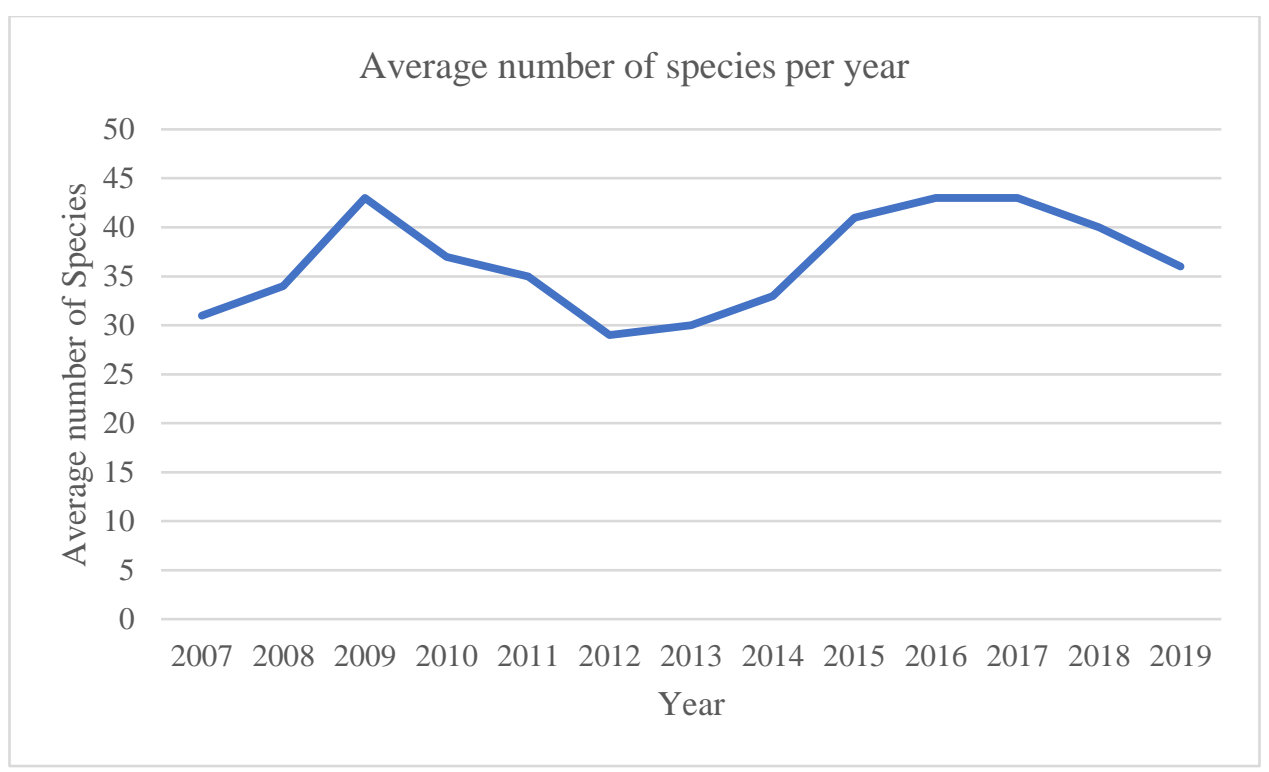

Figure 3: Cyclic pattern of the average number of Species from 2007 to 2019

The average number of species (Table 1) found in the Wetland Park varies every year but, it is quite evident (Figure 3) that the average number of species found in there follows a cyclical pattern. The critical point is that the second cycle reveals an increase in the first cycle. Although there are limitations, which are mentioned above, to advancing environmental sustainability at the Wetland Park, the contributions made by the university are showing results. Hopefully, in the 
course of time, environmental sustainability will continue to improve and achieve an ability for self-maintenance.

\section{Discussion}

Hilltop University contributes towards advancing sustainability in the region and on several levels contributed towards all aspects of sustainability this paper reviewed i.e. social, economic, and environmental. The contribution made by Hilltop University each show headway towards improved levels of sustainability. In all aspects of sustainability, there is an amount of depletion which brings with it complications and limitations. Hilltop University has unique approaches and solutions in each of these areas which have resulted in significant positive outcomes. The university's existence and ability to work with the community and change social perspectives made it possible to reinfuse societal hopes of accomplishment. The sense of accomplishment is a foundation towards growth in social, economic, and environmental sustainability. 


\section{References}

[1] A. D. Cortese, "The Critical Role of Higher Education in Creating a Sustainable Future," pp. $15-22,2003$.

[2] W. L. Filho, "About the Role of Universities and Their Contribution to Sustainable Development," Higher Education Policy, vol. 24, no. 4, pp. 427-438, Sep. 2011.

[3] P. Chatterton and J. Goddard, "The Response of Higher Education Institutions to Regional Needs," European Journal of Education, vol. 35, no. 4, pp. 475-496, 2000.

[4] W. H. Trombley and T. Sallo, "A Collaborative for Academic Excellence," American Higher Education: Journalistic and Policy Perspectives from National CrossTalk, pp. 57-62, 2012.

[5] D. L. Jacobson, "A New Agenda for Education Partnerships Stakeholder Learning Collaboratives," Change: The Magazine of Higher Learning, vol. 33, no. 5, pp. 44-53, 2001. [6] login. [Online]. Available:

https://cierpdata.utep.edu/OnlineFactBook/FAC_Enroll_History.aspx. [Accessed: 30-Jan-2020]. [7] Economic Modeling Specialists Intl., "Demonstrating the Economic Value of The University of Texas at El Paso," January, 2015.

[8] B. M. Hudson, "Regional Economic Effects Of Higher Education," vol. 8, pp. 181-194, 1974.

[9] "Accounting and Financial Reporting," UTEP. [Online]. Available:

https://www.utep.edu/vpba/accounting-and-financial-reporting/departments/financialreporting.html. [Accessed: 30-Jan-2020].

[10] J. Sproul, "Meeting Water Needs at Rio Bosque Wetlands Park : Strategies Involving El Paso Water Utilities", 2011.

[11] S. H. Watts, J. Sproul, and E. Hamlyn, "A Biological Management Plan for Rio Bosque Wetlands Park," October, 2002. 